\title{
Analysis of biomechanical parameters extracted from anorectal manometry of fecally-continent and incontinent patients
}

\author{
Bianca Espindola ${ }^{1}$ \\ Chris Mayara dos Santos Tibes ${ }^{2}$ \\ Huei Diana Lee ${ }^{3}$ \\ Renato Bobsin Machado ${ }^{4}$ \\ André Gustavo Maletzke ${ }^{5}$ \\ Wu Feng Chung ${ }^{6}$
}

Objective: to evaluate the average resulting area from the Pressure $\mathrm{x}$ Time curves resulting from the manometric anorectal exam and compare it with the support capacity of voluntary squeeze. Materials and Methods: the data set was represented by data from 11 exams from continent patients and eight exams from patients with grade III fecal incontinence. The manometric curves were delineated, and the areas and support capacity of voluntary squeeze calculated, by means of the $\mathrm{R}$ computer language and the algorithm developed. Results: the resulting averages for support capacity of voluntary squeeze in continent patients and patients with grade III fecal incontinence were 33.07 seconds and 30.76 seconds ( $p>0.05)$ and the averages for area were $2362.04 \mathrm{mmHg} \times$ second and $947.92 \mathrm{mmHg} \times$ second $(p<0.05)$, respectively. Conclusion: the average resulting area is able to differentiate continent patients from incontinent and is shown to be a possible parameter in the analysis of biomechanical behavior related to the mechanisms of anorectal continence.

Descriptors: Biomechanics; Colorectal Surgery; Physiology.

\footnotetext{
${ }^{1}$ Master's Student, Faculdade de Ciências Médicas, Universidade Estadual de Campinas, Brazil.

2 RN.

${ }^{3} \mathrm{PhD}$, Professor, Universidade Estadual do Oeste do Paraná, Brazil.

${ }^{4}$ Doctoral Student, Faculdade de Ciências Médicas, Universidade Estadual de Campinas, Brazil. Professor, Universidade Estadual do Oeste do Paraná, Brazil.

${ }^{5}$ MSc, Professor, Universidade Estadual do Oeste do Paraná, Brazil.

${ }^{6}$ PhD, Professor, Universidade Estadual do Oeste do Paraná, Brasil. Researcher and Professor, Faculdade de Ciências Médicas, Universidade Estadual de Campinas, Brazil.
} 


\title{
Análise de parâmetros biomecânicos extraídos da manometria anorretal de pacientes continentes e com incontinência fecal
}

Objetivo: avaliar a área média resultante, proveniente das curvas pressão versus tempo, pertencentes ao exame manometria anorretal e confrontá-la com a capacidade de sustentação. Materiais e métodos: a casuística foi representada por dados de 11 exames de pacientes continentes e oito exames de pacientes com incontinência fecal grau III. Por meio da linguagem computacional $\mathrm{R}$ e do algoritmo desenvolvido foram delineadas as curvas manométricas e calculadas as áreas e capacidades de sustentação. Resultados: as médias resultantes da capacidade de sustentação de pacientes continentes e com incontinência fecal grau III foram 33,07 segundos e 30,76 segundos $(p>0,05)$ e as da área, $2362,04 \mathrm{mmHg} \times$ segundo e 947,92 $\mathrm{mmHg} \times$ segundo $(p<0,05)$, respectivamente. Conclusão: a área média resultante foi capaz de diferenciar os pacientes continentes dos incontinentes e demonstra ser um possível parâmetro na análise do comportamento biomecânico, relacionado aos mecanismos de continência anorretal.

Descritores: Biomecânica; Cirurgia Colorretal; Fisiologia.

\section{Análisis de parámetros biomecánicos extraídos de la manometría recto- anal de pacientes con continencia e incontinencia fecal}

\begin{abstract}
Objetivo: evaluar el área media resultante proveniente de las curvas Presión versus Tiempo pertenecientes al examen manometría rectal y afrontarla con la capacidad de sustentación. Materiales y Métodos: la casuística fue representada por datos de 11 exámenes de pacientes moderados y ocho exámenes de pacientes con incontinencia fecal grado III. Por medio del lenguaje computacional $\mathrm{R}$ y del algoritmo desarrollado fueron delineadas las curvas manométricas y calculadas las áreas y capacidades de sustentación. Resultados: los medios resultantes de la capacidad de sustentación de pacientes moderados y con incontinencia fecal grado III fueron 33,07 segundos y 30,76 segundos $(p>0,05)$ y las de la área, $2362,04 \mathrm{mmHg}$ x según y 947,92 mmHg x según $(p<0,05)$, respectivamente. Conclusión: el área media resultante fue capaz de diferenciar los pacientes continentes de los incontinentes y demuestra ser un posible parámetro en el análisis del comportamiento biomecánico relacionado a los mecanismos de continencia rectal.
\end{abstract}

Descriptores: Biomecánica; Cirurgía Colorrectal; Fisiología.

\section{Introduction}

Fecal incontinence (FI) is one of the coloproctological disorders which most contributes to an individual's social alienation, because it interferes in his or her physical and psychological conditions. This is characterized by the loss of control of the physiological mechanisms of defecation, resulting in the unexpected escape of gas and liquid or solid feces via the anal canal(1).

Although the actual incidence of this disorder is not precisely known, it is estimated that it may affect up to $5 \%$ of the general population, with high prevalence among the elderly and women ${ }^{(2-5)}$. It is noteworthy that in young patients, the prevalence of FI is higher in women than in men, and that this factor is related to trauma resulting from obstetric procedures ${ }^{(4,6)}$.
The physiology of control of fecal continence (FC) is complex and depends on the integrated action of various factors, such as the musculature of the sphincter and the pelvic floor muscles, the presence of the rectoanal inhibitory reflex, the rectoanal angle, the rectal capacity and compliance, the integrity of the sensory-motor function of the anorectal anatomical region, the patient's neurological state, the consistency of the feces and the bowel transit time ${ }^{(1,7-8)}$. In situations which entail the loss of control of these physiological mechanisms of defecation, as a result of the fact, the scenario of fecal incontinency may arise. This being so, this etiopathogenic condition may be present in old age or be associated with infirmities of clinical or surgical 
areas such as diabetes mellitus, multiple sclerosis, inflammatory bowel disease, and the post-operative of hemorrhoid disease, and resection of the colon and the rectum $^{(4,9-10)}$.

Various complementary exams are currently used to help in understanding the etiology, detection and classification of FI, such as endoanal ultrasound, pudendal nerve latency time, perineometry and anorectal manometry (AM), this last test being one of the most used(3,11-14). The physical parameters related to the mechanism of defecation, such as presence or absence of the inhibitory rectoanal reflex, resting pressure, maximum voluntary contraction pressure (MVCP) and support capacity of voluntary squeeze (CS) are analyzed through the use of this diagnostic method. The last two attributes are the most requested in the evaluations ${ }^{(1,15)}$. However, according to the studies undertaken, patients diagnosed as incontinent using the MVCP and CS magnitudes are found within the range of normality ${ }^{(1,16-19)}$. This fact indicates that these parameters may evaluate the patient's actual situation incompletely.

For this reason, with the aim of contributing to the broadening of knowledge in the field of anorectal biomechanics, in this work a comparative analysis was performed between the behavior of the physical parameter represented by the average resulting area (ARA) and one of the attributes most requested in routine clinical practice, $\mathrm{CS}$, to promote the differentiation of continent patients and those with grade III (GIII) FI.

\section{Method}

This work was carried out in accordance with the Research Ethics Committee's precepts (Protocol number 0481.0.146.000-09/Approval 602/09).

The data set analyzed was represented by data from 19 AM exams belonging to 19 patients, of which 11 were from patients in a condition of fecal continence (FC) and 8 from patients with FI GIII. These tests were performed under the supervision of a single evaluator, in the Anorectal Physiology Laboratory of a Public Institution in the state of São Paulo between September 1995 and August 1996. Exams of patients submitted to AM who did not present sufficient data for classification by the specialist were excluded.

The materials used for the analyses were:

- Computer Intel ${ }^{\circledR}$ Pentium 4 CPU $2.80 \mathrm{GHz}, 2.79 \mathrm{GHz}$,
1 GB of RAM and Microsoft Windows XP Professional operating system, Version 2002, Service Pack 2;

- $\mathrm{R}$ version $2.9 .1^{\circledR}$ programming language (LR);

- Java Development Kit $1.6^{\circledR}$ programming language;

- Tinn R software version $1.19^{\circledR}$ for assistance in developing algorithms in the LR;

- Data referent to the 19 patients' AM tests, stored in 3/4 diskettes in the plaintext.

With the aim of analyzing the ARA of the periods of voluntary squeeze from the Pressure $x$ Time curves, and the resultant average of the support capacity (RCS) for each AM exam, the following stages were undertaken: (1) Classification of the exams; (2) Acquisition of the data and calculation of the parameters; and (3) Analysis of the data.

In Stage (1) tables were devised with information such as the identification of the patient by means of a letter, age, sex, clinical history, date of the exam and results of the exam. Afterwards, the AM tests were classified and grouped by the specialist according to the protocol described below ${ }^{(1)}$ :

- Continent: no fecal urgency, easy hygiene, no use of clothing protectors and social and professional activities maintained as normal;

- Grade I (GI): occasional loss of gases, defecation urgency in the event of diarrhea, and preservation of social and professional activities;

- Grade II (GII): frequent escape of gases and liquid feces, defecation urgency of solid feces and partial compromising of the individual's social and professional activities;

- Grade III: incontinence of solid feces, daily escape of feces, fecal urgency, obligatory use of clothing protectors and social and professional activities rendered impossible.

In Stage (2), by means of the software developed based on the $L R^{(20)}$, eight graphs of Pressure $x$ Time were delineated, derived from the acquisition of the pressure values of the eight channels of the catheter for AM. Each graph records three periods of voluntary squeeze of the anal sphincter, thus resulting in 24 pressure periods. Afterwards, the specialist analyzed the 24 moments of voluntary squeeze originated by the eight sensors of the AM test and selected three periods derived from one channel for the demarcation of the CS In this context the starting and finishing points of the voluntary squeeze were defined and, in the remaining 21 moments, the CS was defined automatically by the software developed (Figure 1). 

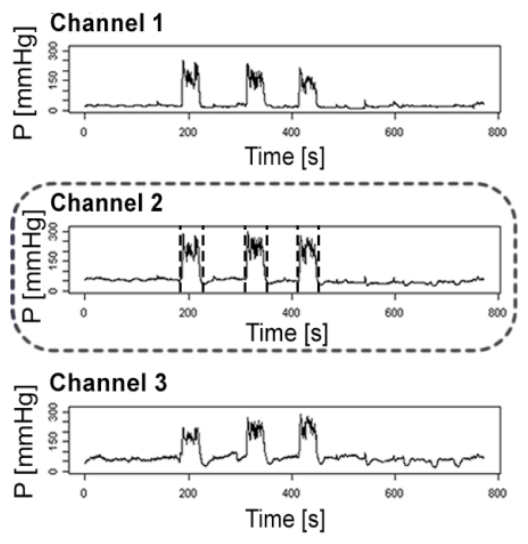

.

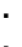

Channel 8

a)
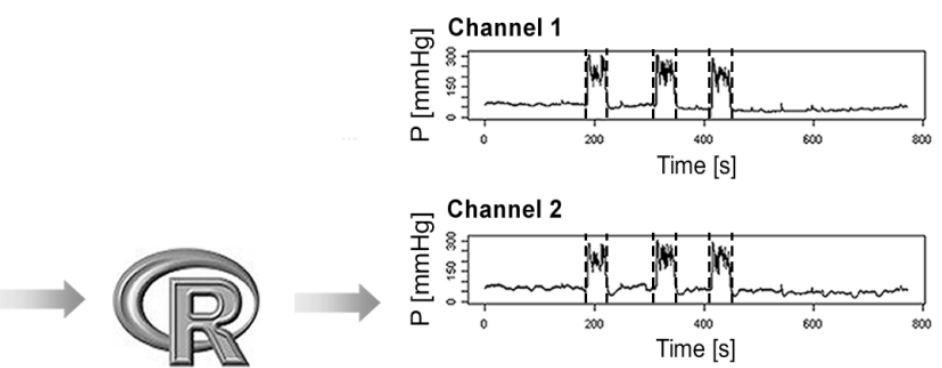

b)

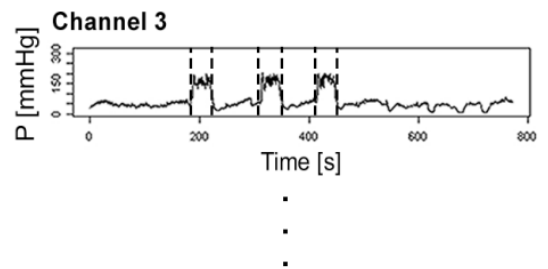

Channel 8

c)

Figure 1 - Figure representative of the determination of the CS: a) selection and demarcation of the CS by the specialist, in three curves produced by a catheter, b) and c) calculation and determination of the $\mathrm{CS}$, through the LR, in the remaining 21 graphs of the anorectal manometry belonging to the same patient

After these actions, the areas under the Pressure $x$ Time curves (APT) of the AM exams were determined, using the method of Numerical Integration Trapezoidal
Rule and were represented by the interval between the initial and final points of the voluntary squeeze

(Figure 2).

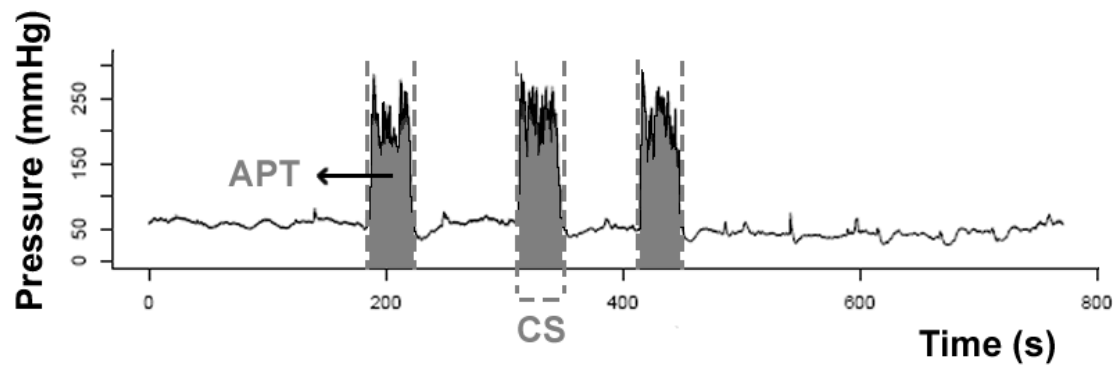

Figure 2 - Schematic representation of the limits of the voluntary support of the external anal sphincter and determination of the area, under one of the Pressure $x$ Time curves from the anorectal manometry exam

In Stage (3), the averages and the standard deviations (SD) of the CS and APT were calculated by the software developed. Following that, the values arising from the exams of the patients in conditions of FC were compared with the results of the tests of individuals with FI GIII, fixing the level of rejection of the null hypothesis at the value of $p \leq 0.05$.

\section{Results}

The result of the voluntary support of each patient with condition of continence and FI GIII, and the parameters such as the averages and standard deviations, are presented in Table 1. 
The ARA values derived from the Pressure $x$ Time curves for each patient in a condition of continence or FI GIII, and the parameters such as averages and standard deviations, are presented in Table 2.

Table 1 - Table representative of the RCS, the average, and the standard deviation of the patients in conditions of FC and FI GIII. Foz do Iguaçu, Paraná, Brazil, 2012

\begin{tabular}{cccc}
\hline FC & RCS (second) & FI & RCS (second) \\
\hline A & 35.42 & A & 38 \\
B & 28.92 & B & 29.63 \\
C & 32.21 & C & 17.71 \\
D & 31.58 & D & 31.17 \\
E & 33.29 & E & 35.96 \\
F & 31 & F & 40 \\
G & 26.96 & G & 25.46 \\
H & 36.83 & H & 28.13 \\
I & 29.79 & - & - \\
J & 37.75 & - & - \\
K & 40 & - & - \\
\hline Average & 33.07 & Average & 30.76 \\
SD & 4.03 & SD & 7.29 \\
\hline
\end{tabular}

FC: fecal continence; RCS: resultant average of the support capacity; FI: fecal incontinence; SD: standard deviation.

Table 2 - Table representative of the ARA, the average and the standard deviation of the patients in condition of FC and FI GIII. Foz do Iguaçu, Paraná, Brazil, 2012

\begin{tabular}{cccc}
\hline FC & ARA (mmHg. second) & FI & ARA (mmHg. second) \\
\hline A & 1984.03 & A & 806.29 \\
B & 1702.35 & B & 1046.78 \\
C & 3927.81 & C & 303.59 \\
D & 2406.33 & D & 988.52 \\
E & 1785.19 & E & 615.06 \\
F & 2237.66 & F & 1615.29 \\
G & 1129.02 & G & 591.70 \\
H & 3999.87 & H & 1616.16 \\
I & 2826.59 & - & - \\
J & 1571.22 & - & - \\
K & 2412.35 & - & - \\
\hline Average & 2362.04 & Average & 947.92 \\
SD & 917.96 & SD & 474.53 \\
\hline
\end{tabular}

FC: fecal continence; ARA: average resulting area; FI: fecal incontinence; SD: standard deviation.

The result of the statistical comparisons performed between the continent patients and those with FI GIII, and their respective ARA and RCS is described in Table 3.
Table 3 - Table representative of the statistical comparisons undertaken between the ARA and CS of the continent patients and the individuals with FI GIII. Foz do Iguaçu, Paraná, Brazil, 2012

\begin{tabular}{lc}
\hline \multicolumn{1}{c}{ Comparisons } & P-value \\
\hline RCS FC $\times$ RCS FI GIII & 0.3872 \\
ARA FC $\times$ ARA FI GIII & 0.0010 \\
\hline
\end{tabular}

RCS: resultant average of the support capacity; FC: fecal continence; FI: fecal incontinence; GIII: grade III; ARA: average resulting area.

\section{Discussion}

The mechanisms involved in FI are complex. Currently, various supplementary exams are used in clinical practice to help in the investigation, evaluation, quantification and determination of this etiopathogenic condition, and they may be represented by radiological and ultrassonographic investigations and biomechanical tests such as the $\mathrm{AM}^{(1,14,21)}$.

Since it was introduced in 1965, anorectal manometry has become one of the most important methods for evaluating FC, due to its efficacy, ease of use and relatively low $\operatorname{cost}^{(22)}$. Since this date, various studies have been done using AM, and, considering this, this method has become one of the most requested for understanding the physiology of defecation and for monitoring infirmities related to $\mathrm{FI}^{(3,11-12)}$. Through this exam, various physical parameters of anorectal biomechanical behavior may be analyzed, such as resting pressure, rectoanal inhibitory reflex, MVCP and $\mathrm{CS}$, the last two attributes being the most used by the specialists $^{(1,15)}$. It is worth emphasizing that, despite the two attributes mentioned being widely requested in the investigation of $\mathrm{FI}$, doubts still remain regarding these physical parameters' relationship to the actual clinical situation presented by the incontinent patient, as measurements of MVCP and CS found in these patients may have values similar to those found in continent persons ${ }^{(1,16,23-25)}$.

Within this ambit, researchers have shown in a previous work that $39 \%$ of the 36 incontinent patients had MVCP within normal limits ${ }^{(24)}$. In a separate study related to $A M$, other investigators reported that $54 \%$ of the incontinent patients had normal MVCP in line with the following distribution: GI, 62\%, GII, 60\% and GIII, 
$7 \%$. The same study observed that $78 \%$ of the patients with FI did not have adequate CS and that in $75 \%$ of these patients, the MVCP was below the normal(1).

Considering these aspects, there is the possibility that the physical parameters derived from the AM may contribute in the study of the physiology of continence and in the act of defecation, but these demand better analysis of the same and of other methods which may contribute to a more complete understanding of this complex mechanism.

In this way, in the present work, two physical magnitudes derived from the anorectal manometry test were analyzed. These parameters were represented by the average resulting of the CS and by the average resulting area derived from the Pressure $x$ Time curves of the patients' AM exams, with this last magnitude being original to the studies of the manometric dynamic of defecation.

It should be stressed that the exams used in this work were always administered by a single specialist and in the same service. This characteristic is fundamental, as it demonstrates the concern over the homogeneity of the undertaking of the exam and the precision of the results achieved. On the other hand, it significantly reduces the quantity of samples, principally when this data is from a hospital or teaching institution. For this reason, training must be carried out with the students, residents and teams as a whole with the aim of achieving greater homogeneity in the data arising from the AM exams, so as to achieve maximum precision in the results.

The attributes such as age, sex and type of surgery undertaken may also affect the results' accuracy, however, it was decided to analyze all the patients selected randomly during September 1995 to August 1996, who met the criteria proposed in the exclusion protocol $^{(1)}$. In this way, it was possible to investigate the population of patients who were submitted to the anorectal manometric test in the Coloproctological department of a public institution in the state of São Paulo during the period of the study.

For the calculation of the RCS and of the ARA, software using the computer language $\mathrm{R}$ was developed. The choice of LR in the development of the software for assisting the studies of AM was based in the fact it is open source and robust, making it ideal in the academic setting, bearing in mind that it facilitates in resolving the problem of paid-for software licenses ${ }^{(20,25)}$.

The averages resulting from the CS found in the groups of continent patients and in the patients with FI GIII were 33.07 seconds and 30.76 seconds, respectively. Through statistical analysis, it was observed that there was no significant difference for $p$-value < $0.05(p=0.3872)$. This characteristic demonstrates that this physical attribute was unable to distinguish, in the data set analyzed, the presence or not of FC.

This result, when compared to another study carried out, did not demonstrate significant similarity considering the CS parameter in determining the conditions of fecal continence and incontinence. It is believed that this difference may be explained by the combination of parameters such as the specificity and sensitivity found by this author, that is, the values of $93 \%$ and $78 \%$ respectively ${ }^{(1)}$. In this context, through this relationship, there is the inference that studies of greater depth - such as prospective studies with analysis of this physical attribute - may contribute to a better understanding of this issue.

Another parameter analyzed in the present work is the ARA. This physical magnitude is obtained through calculating the result of the areas of the 24 moments of voluntary squeeze and support derived from the graphs for Pressure $x$ Time of each AM exam. This value corresponds to the result of the energy accumulated by the group of muscles responsible for continence and is based in the inter-relation of the physiological actions of these anatomical structures(25).

In this work, the results obtained from the ARA of the control group and the group of patients with $\mathrm{FI}$ GIII were $2362.04 \mathrm{mmHg} \times$ second and $947.92 \mathrm{mmHg} \times$ second, respectively. Through the statistical analysis, it could be observed that there was a significant difference for $p$-value $<0.05(p=0.001)$.

The dispersions of the RCS found in the groups of continent and incontinent patients were $12.18 \%$ and $16.32 \%$, while in the ARA, these were $38.86 \%$ and $50.06 \%$, respectively. Although the dispersions of the data of the ARA are higher, it is important to take into account that the RCS evaluates only one physical attribute, time, while the ARA analyzes two physical magnitudes fundamental for the biomechanical behavior of defecation, pressure and time, pressure being directly related to the result of the forces exercised by the muscles per unit of area.

In biomechanics, physical attributes of muscular action are characterized most completely through the energy spent for the completion of a task, this being equivalent to the product of the force of the muscle by the amplitude of the contraction of the same. The muscle's force is directly related to the number of muscle 
fibers, and the amplitude of contraction depends on the degree of shortening of these structures(25).

In this way, the muscles which make up the pelvic floor work together for maintaining control of continence, and this condition depends on various factors such as the patient's neurological state, the volume and consistency of the feces, the rectal compliance and sensitivity, the function of the sphincters of the anus and the recto-anal inhibitory reflex. All these attributes are correlated and the response is directed and attributed principally by the action of the musculature of this anatomical region. This being so, in accordance with these characteristics, one may say that the work done by the muscles is represented by the result of the forces exercised by the whole set of muscles responsible for the maintenance of continence.

Currently, various works have as their scope the study of other methods and parameters for the evaluation of the biomechanics of defecation. The use of these tools can help in new fields of research, contributing to the understanding and elucidation of doubts regarding anorectal physiology, and, contribute in the diagnosis, treatment and prevention of this serious etiopathogenic condition.

\section{Conclusion}

The analyses accomplished in this work permit the following conclusions:

The average result of the support capacity of the pressure of voluntary squeeze was not shown to be adequate for the differentiation of continent patients and patients with grade III fecal incontinence;

The average resulting area derived from the Pressure $x$ Time curves of the anorectal manometry exams were shown to be adequate for differentiating patients with the characteristic of continence and patients with grade III fecal incontinence and are shown to be a possible parameter in the analysis of the biomechanical behavior related to the mechanisms of anorectal continence.

\section{Acknowledgements}

We would like to express our gratitude to professors Cláudio Saddy Rodrigues Coy and João José Fagundes for their support in all phases of the study.

\section{References}

1. Saad LHC, Coy CSR, Fagundes JJ, Ariyzono ML, Shoji

N, Góes JRN. Quantificação da função esfincteriana pela medida da capacidade de sustentação da pressão de contração voluntária do canal anal. Arq Gastroenterol. 2002;39(4):233-9.

2. Nelson R, Norton N, Cautley E, Furner S. Communitybased prevalence of anal incontinence. JAMA. 1995;274(7):559-61.

3. Oliveira L. Incontinência fecal. JBJ, J. b. gastroenterol. 2006;6(1):35-7.

4. Toglia MR. Pathophysiology of anal incontinence, constipation and defecatory dysfunction.

Obstet Gynecol Clin N Am. 2009;36(3):659-71.

5. Fruehauf $H$, Fox MR. Anal Manometry in the investigation of fecal incontinence: Totum pro parte, not pars pro toto. Digestion. 2012;86:75-7.

6. Araújo NM, Oliveira SMJV. Uso de vaselina líquida na prevenção de laceração perineal durante o parto. Rev. Latino-Am. Enfermagem. 2008;16(3):375-81.

7. Gordon $\mathrm{PH}$. Anorectal anatomy and physiology. Gastroenterol Clin North Am. 2001;30(1):1-13.

8. Barleben A, Mills S. Anorectal anatomy and physiology. Surg Clin North Am. 2010;90(1):1-15.

9. Rao SSC. State of the art: Pathophysiology of adult fecal incontinence. Gastroenterology. 2004;126(1):S14-S22. 10. Pereira APS, Cesarino CB, Martins MRI, Pinto $\mathrm{MH}$, Netinho JG. Associação dos fatores sociodemográficos e clínicos à qualidade de vida dos estomizados. Rev. Latino-Am. Enfermagem. 2012;20(1):93-100.

11. Bessa MO, Morreira HJ, Morreira JPT, Silva E, Isaac RR, Almeida AC. Impacto da eletromanometria anorretal na avaliação de 293 pacientes consecutivos encaminhados ao ambulatório de fisiologia anorretal. Rev Bras Coloproctol. 2008;28(1):26.

12. Rao SS. Advances in diagnostic assessment of fecal incontinence and dyssynergic defecation. Clin Gastroenterol Hepatol. 2010;8(11):910-9.

13. Riesco MLG, Caroci AS, Oliveira SMJV, Lopes MHBN. Avaliação da força muscular perineal durante a gestação e pós-parto: Correlação entre perineometria e palpação digital vaginal. Rev. Latino-Am. Enfermagem. 2010;18(6):1138-44.

14. Balsamo F, Filho PRR, Pozzobon BHZ, Castro CAT, Formiga GJS. Correlação entre achados manométricos e sintomatologia na incontinência fecal. Rev Bras Coloproctol. 2011;31(1):39-43.

15. Felt-Bersma RJF, Klinkenberg-Knol EC, Meuwissen SGM. Anorectal function investigations in incontinent and continent patients. Dis Colon Rectum. 1990;33(6):47985.

16. Felt-Bersma RJF, Meuwissen SGM. Anal manometry. Int J Colorectal Dis. 1990;5(3):170-3. 
17. Freys SM, Fuchs KH, Fein M, Heimbucher J, Sailer

$M$, Thiede $A$. Inter and intraindividual reproducibility of anorectal manometry. Langenbecks Arch Surg. 1998;383(5):325-9.

18. Siproudhis L, Bellisant E, Pagenault M, Mendler $\mathrm{MH}$, Allain $\mathrm{H}$, Bretagne JF, et al. Fecal incontinence with normal anal canal pressure: Where is the pitfall? Am J Gastroenterol. 1999;94(6):1556-63.

19. Labermeyer S, Seidl H, Scalercio N, Gundling F, Schmidt T, Schepp $W$, et al. Is the accuracy of anorectal manometry (ARM) worthwile in patients with fecal incontinence (FI) Gastroenterology. 2011;140(5):161.

20. Shiki SB, Lee HD, Burin ELK, Niz MAK, Coy CSR, Fagundes Jj, et al. Desenvolvimento de um sistema para a análise de curvas provenientes de exames de manometria ano-retal. III Congresso da Academia Trinacional de Ciências, Foz do Iguaçu, Paraná; 2008. p. 1-8.

21. Perry JD, Perry LM. Advances in the diagnosis and treatment of fecal incontinence. Adv Nurse Pract. $1999 ; 7(10): 55-7$.

22. Schuster MM, Hendrix TR, Hookman P, Mendeloff AI. Simultaneous manometric recording of internal and external sphincteric reflexes. Bull John Hopkins Hosp. 1965;116:79-88.

23. Raza N, Bielefeldt K. Discriminative value of anorectal manometry in clinical practice. Dig Dis Sci. 2009;54(11):2503-11.

24. Rasmussen OO, Ronholt C, Alstrup N, Chistiansen J. Anorectal pressure gradient and rectal compliance in fecal incontinence. Int J Colorectal Dis. 1998;13(4):157-9.

25. D'Ávila CRA, Espindola B, Tomim DH, Lee HD, Coy CSR, Fagundes JJ, et al. Estudo do parâmetro área máxima sob a curva pressão versus tempo proveniente do exame de manometria ano-retal em relação à grandeza física pressão máxima de contração voluntária de pacientes com continência e incontinência fecal grau III. IV Congresso da Academia Trinacional de Ciências, Foz do Iguaçu; 2009. p. 1-8. 